The base: a case of infrastructural governance of labour outmigration in China

BIAO XIANG

Institute of Social and Cultural Anthropology, University of Oxford

Correspondence address: Biao Xiang, 51/53 Banbury Road, Institute of Social and Cultural Anthropology, Oxford, OX2 6PE. biao.xiang@anthro.ox.ac.uk 


\title{
The base: a case of infrastructural governance of labour outmigration in China
}

\begin{abstract}
Since the early 1990s, the Chinese government replaced strict control over outmigration with measures of 'infrastructural governance'. Instead of dictating who can and who cannot leave, the state manages migration by influencing the sociotechnical conditions of mobility, for instance by defining what responsibilities commercial intermediaries should shoulder and what training a migrant should receive before departure. This article unpacks infrastructural governance by examining the working of 'base', or jidi in Chinese. A base is a tight cluster of public and private institutions in a labour source place, designated by the government as an important player in the recruitment of migrant workers. The base manages migration by conditioning the activities that lead to migration, such as how people choose destinations, make payments, and deal with uncertainties in preparing for migration. The base also works on migrants' relations with family members, village cadres and fellow migrants in order to shape their mobilities. The ethnographic research on the base shows that, infrastructural governance regulates migration effectively, but makes migration more complicated and more costly for the migrants. Infrastructural governance empowers commercial intermediaries and local government, and as such affects broader social relations in the community.
\end{abstract}

Keywords

infrastructural governance, China, labour migration, politics of mobility

Over one million Chinese citizens were working overseas legally on temporary contracts at the end of 2015 (Ministry of Commerce 2016), compared to just below 58,000 in 1990 (Zhongguo duiwai jingji maoyi chubanshe 1991: 654) ${ }^{1}$. Not only has the number of outmigrants increased, the meaning of cross-border mobility for Chinese citizens has also changed significantly over the last three decades. Before the 1990s, labour migration was a state-organized project, and only employees of state-owned enterprises or large collective firms could be dispatched. By the 1990s, in contrast, any citizen could seek to work overseas. With the streamlining of private passport regulation in the 2000s, anyone is free to leave as long as a visa from the destination country is secured. Increased freedom of mobility, 
however, does not mean that migration has become less regulated. Since the early 1990s, the Chinese government has drawn on what I call methods of 'infrastructural governance'. Although the state no longer dictates who can and who cannot leave, it manages migration closely by influencing the sociotechnical conditions of mobility, for instance by defining the functions and responsibilities of commercial intermediaries, deciding on what training a migrant should receive before departure, as well as specifying the types of documents and how and when they should be submitted. The mode of governance can thus be described as 'infrastructural' (for a detailed discussion on 'migration infrastructure', see Xiang and Lindquist 2014).

Infrastructural governance manages migration not as the single action of a migrant, but as a series of activities of multiple agents that comes together to constitute what is called 'migration'. In many cases, these activities do not lead to actual migration at all. For this mode of governance, how a person crosses an international border is only a minor concern, while the plans, potentialities, readiness and failures of migration are equally, if not more, important. This article, following mobility studies and anthropological reflections on infrastructure and mediation (e.g. Mazzarella 2004; Hull 2008; Chu 2010; Collier 2011; Larkin 2013), disentangles how labour migrants' mobility is constituted and more importantly, how the state actively conditions this process of constitution as a basis of migration regulation.

This article does so by examining the operation of the 'base' in labour outmigration management. The term of 'base' (jidi), a shorthand of 'base for labour dispatch' (waipai laowu jidi), can refer to three things, depending on the context. First, a base can mean a place that, usually in the countryside, has abundant human resources where migrant workers are recruited from. Second, the term of base can refer to a particular intermediary in that place who recruits, trains and manages migrants. Finally, after 2010, a base can also mean a public institute set up by a county government that aims to monopolize the recruitment business at that county. The official name of the institute is 'Labour Service Platform', but it is commonly called a 'base' in daily conversation. The county is designated by the central government. All licensed labour placement companies are supposed to source workers from the approved Labour Service Platforms only. A manager of a licensed labour placement company may say something like this: 'I am going to our base today. Our base told me that they are having a difficult time as they are pushed around by the new government base.' In this sentence, the three 'bases' means respectively a place, an intermediary and the new public institute. 
For our analytical purpose, the base can be defined as a place-based cluster of public and private institutions. The base represents a particular administrative way of organizing migration infrastructure, which attaches special importance to the migration infrastructure in the stage of recruitment and in migrants' home communities. The base starts managing migration well before the migration journey starts, and ends migration management only after the migrant returned. Even when migrants are at work overseas, intermediaries and government agencies in the base place pressure their family members to prevent migrants from absconding from their employers. This is because the base intermediaries and government are concerned that the absconded may develop migrants' transnational networks, which may facilitate illegal migration from the base place in the long run. A base is not a ‘third party’ agency that mediates between migrants and employers; instead it serves as the central locus where a certain type of mobility is organized while other forms prevented. The functions of the base play important roles in the development of the infrastructural governance of migration. The multiple meanings of the term of base reflect the multifacetedness of the base as well as the fact that the base has evolved over time in its composition.

My ethnographic research on the base shows an important effect of infrastructural governance, that is the intensification of mediation of labour migration. More intermediaries, both private and public, are involved. Most surprisingly, the local government became more interventionist than before, despite that infrastructural governance is meant to accelerate liberalization. While previously a small number of ministries (primarily the Foreign Economic Liaison Ministry) and their associated enterprises deliberated on matters concerning labour deployment, now multiple local government agencies at base places across China have a hand in the management of migration. Commercial intermediaries, formally independent of government, have to work closely with government. The complication of the procedure and the involvement of large numbers of intermediaries mean that migrants have to pay more to go overseas. While the case of base may be unique to China, the increasing importance of migration infrastructure, the intensification of mediation, and the rising costs of migration on the migrants' part are common phenomena across Asia (Xiang and Lindquist 2014). The case of the base signals governments' increasing dependence on infrastructural devices in managing migration and the likely consequences of this trend in Asia.

This article is part of a larger project on the governance of transnational labour mobility from northeast China to Japan, Singapore and South Korea. In the 1990s, these three countries replaced Africa and the Middle East as the top destinations, responsible for more 
than 35 percent of all labour migrants from China worldwide by 1999 (Yin 2002, 16). This happened in exactly the same period as infrastructural governance was introduced. I carried out intensive field research between July 2004 and November 2007 in the four countries, and continue meeting migrants, recruiters, employers, government officials, and NGO activists whenever possible to date. Of the total of nearly 200 interviews recorded, 19 are with base intermediaries and their subagents in townships and villages, mostly in Fu Prefecture of Liaoning province in northeast China. The subagents, commonly known as 'legs', were normally individuals with certain social standing, such as retired grassroots cadres and school teachers. Important information about bases was also gained from other informants, particularly would-be migrants. In the remainder of the article I will first elaborate on the concept of infrastructural governance. I will then discuss how the base emerged as an important part of infrastructural governance. The main part of the article details the work of the base in conditioning outmigration. The conclusion reflects on how the present case may contribute to mobility and infrastructure studies.

\section{Infrastructural governance: governing by conditioning}

The term ‘infrastructural governance’ is inspired by Michael Mann’s concept of infrastructural power (1984). By infrastructural power, Mann refers to the type of power that a centralized state exercises across a large territory in a standard and predictable manner, for instance in tax collection and population registration. In contrast to despotic power that is imposed over society, infrastructural power works through society. Infrastructure power historically rose alongside with the development of bureaucracy, population literacy, and various social-techno systems such as communication and transportation. Infrastructural power is precisely what the Chinese state aimed to cultivate since the end of 1970s when it started reforming itself from a mobilizational-despotic regime to a rule-based regulatory system (Yang 2004; for the development of a regulatory framework governing exit and return, see Xiang 2003; Liu 2007, 2009). The introduction of infrastructural governance of labour outmigration was part of this endeavour. Official documents and policy research on labour outmigration in the 1990s repeatedly called for reforms that would enhance market mechanisms and allow for more individual freedom to work overseas. These measures, they argued, would make the process of migration more standardized, transparent, and efficient, therefore would reduce migrants’ costs (e.g. He 1994; Long 1995; Gao 2000, 77; Dou 2004). Similar to how infrastructural power differs from despotic power, infrastructural governance 
replaced top-down control with efforts of channelling—or 'infrastructuring'—individuals' movements.

Infrastructural governance is more than governing with infrastructure. Any mode of governance relies on infrastructure. As we shall see below, the social infrastructure comprising command chains between government agencies were indispensable for the old model of control. What makes infrastructural governance distinct is that it foregrounds infrastructure as the central subject of governance, as opposed to treating it as a tool in the background (see also Lindquist and Xiang, forthcoming). As an example, the Chinese government in the early 2000s identified commercial intermediaries, rather than migrants or foreign employers, as the focus of outmigration management (Ministry of Labour and Social Security et al. 2002; various unpublished speeches at the national conferences on overseas employment in 2004, 2005 and 2006 organized by the International Exchange Centre affiliated to the same ministry) ${ }^{2}$. This was because the government recognized that, although it was the migrant who moved, it was the intermediaries that shaped the moves, thus governing intermediaries would be more effective than governing migrants.

The foregrounding of infrastructure in infrastructural governance is not only a tactical move. It is also a matter of principle. The question of how one migrates, instead of who migrates, becomes crucial because every citizen is now free to move. In this sense, the concept of infrastructural governance may not be applicable to immigration management in most countries because, despite of the increasing importance of technological infrastructure in border policing, immigration control is predicated on the principle of exclusion: no one is allowed to enter unless allowed to beforehand. Infrastructural governance of migration therefore must be considered together with broader changes in political economy. It is against shifts in the broad historical background that the significance of micro operations of the base can be better appreciated.

\section{A history of the base: 'Moving the frontier of control forward'}

A base is always defined in relation to a 'window'. A 'window' is a large company with an exclusive license that confers authority to sign international contracts and finalise legal documents for migration, a license that most bases do not have. Most windows are in Beijing, Shanghai and capital cities of provinces, far removed from labour source places. Typically, a window company signs placement contracts with a foreign client, and then passes on the recruitment and related tasks to its bases. They sometimes do so via other intermediaries, in 
which case forming long intermediary chains. While windows control the access to permits to exit, which is a conventional means of migration control, it is the bases that manage how a person becomes a migrant and how migration comes into being.

The window-base relation has its origin in the state foreign aid projects that sent (mainly skilled) personnel to other Third World countries between the 1950s and the end of 1970s. During that period, when the central government decided to start a project overseas, the Foreign Economic Liaison Ministry (later the Ministry of Commerce) would require the bureau in a particular province with suitable expertise and labour force to implement the project. The provincial bureau might in turn ask municipality offices to do the same. Finally the local government tasked state-owned enterprises in its locality to select employees to be dispatched. This chain of command transmuted into chains of intermediaries starting from the early 1980s. The central government first turned a number of functioning arms of ministries (for instance the project bureau of the Construction Ministry) into state-owned companies to carry out international projects on a commercial basis under the coordination of the Foreign Economic Liaison Ministry. They became the earliest window companies. As these companies did not have workers of their own, they sourced workers from smaller state-owned companies, who became their bases.

The window-base relation became looser over time. With the deepening of the marketoriented economic reform, windows approached any units of their choice for workers. At the same time, base units started recruiting workers from outside instead of dispatching their own employees; in other words, they became quasi-intermediaries. Other types of entities besides state-owned enterprises, including local government departments, public institutes and especially private companies, also joined to serve as bases. Active base units brought about a 'culture of migration' in the place where they were located, where transnational migration became a normal or even desirable life choice for the local population. This in turn attracted window companies to the place for recruitment. Thus, in addition to base intermediaries, we now have base places. The term base now means both a place and an intermediary.

Developments in the 1990s were somewhat contradictory. Bases were once expected to disappear, but soon became more important. In the early 2000s, the government started privatizing window companies, and encouraged them to become fully-fledged enterprises rather than empty-shell brokers. Windows which outsourced recruitment tasks to bases were criticized. This reform was meant to create a market-oriented infrastructure that would make migration easier and cheaper. Soon afterwards, however, the government identified the development of bases as a top policy agenda. The Ministry of Commerce and the associated 
China International Contractors Association-the central agencies in charge of international labour outmigration after 2010 when they took over the relevant responsibilities from the Ministry of Labour-decided to make designated bases into exclusive sources of labour force for all windows. The Ministry subsidizes the designated bases (the 'Labour Service Platforms') and evaluates them every year in order to enhance their base functions.

The government made the U-turn because it realized that bases remained indispensable for the functioning of windows after the privatization of window companies. When asked why windows, now independent commercial entities, continued to work with bases rather than organized recruitment themselves at a lower cost, most window managers pointed to 'culture'. 'Only [in places] where many people want to go abroad, you can choose good people quickly.' Migration culture is also referred to by the term 'climate'. 'Once the climate [for outmigration] is ripe, the job [of recruitment] will be easy'. When a place has developed a migration culture or climate, 'one doesn't need to explain what it is like to work in South Korea or Japan', and 'people dare to lend money to would-be migrants.' Base intermediaries are hence instrumental in cultivating and maintaining such migration culture.

But what really makes bases irreplaceable is that the windows are seeking a particular type of migration culture. This migration culture is very different from what has been widely discussed in existing literature (Reichert 1981; Massey et al. 1993; Ali 2007; Horvath 2008; Levitt 2001, Gardner 1995; Pieke et al 2004; Findlay and Li 1997). Windows for instance constantly emphasized the importance of guarding against an 'abscond culture'. If a migrant ran away from the employer while overseas, I was told, fellow home-town migrants, even if not working in the same factory, would become 'destabilized', as a base manager put it, and may follow the example. Future migrants from the same home communities would also be considered more likely than others to go underground. If more than a certain number of migrants were to abscond, the window company would risk losing its foreign clients, or even become delicensed by the Chinese government and banned by the governments of Japan, South Korea and Singapore, all of which admit large numbers of temporary labour migrants but impose strict control and take a hard line especially against those who abscond or overstay. Base intermediaries, as we shall see below, are effective in supressing the 'wrong' migration culture.

The government made the U-turn also because bases in some ways became more important for regulators after windows were privatized. Previously the windows were responsible for preventing migrants' misbehaviour, which was an effective method when the windows were owned by the government and the workers were sent out collectively as 
project teams. But it became impractical when recruitment became business dealings between commercial intermediaries and individuals. The government thus saw the necessity, as official documents have it, to 'move the frontier of control forward'-to migrants' home communities. Thus, although originating in the old control system, it is in the era of infrastructural governance that the base became a strategic site for regulation.

\section{Base as government-intermediary nexus}

The double meaning of 'base'—as an intermediary and as a place—-though sometimes linguistically confusing, accurately captures what a base really is. The central player in a base place is an intermediary. But in order to function the intermediary must work with other actors, including government agencies, public institutes and commercial players. These connections give the base intermediaries both public trust and coercive power that they need. The connections are place-based, and are embedded in local society. Being locally bound, they are dominated by the local government. A base is fundamentally a tight cluster of public and private institutions.

As part of such government-intermediary nexus, public institutions that are keen to earn extra-budgetary incomes are the most desirable base intermediaries for some windows. Local People's Congress, Political Consultative Conference and 'mass organizations' such as Youth League and Women's Federation are particularly popular as they are technically outside of the government structure and can circumvent the central state's rule that government departments should stay away from business. Public institutions are preferred because wouldbe migrants trust them, especially after the mid-2000s when scams about private intermediaries were widely reported. Talent Nets, a window company in Shenyang, the capital city of Liaoning, appointed a government vocational training college in Fu Prefecture as a base in 2007. A special memo signing ceremony was held, a department director of the prefecture labour bureau was invited to unveil the plank 'Recruitment Base of Talent Nets' on the gate of the school. The CEO of Talent Nets called this a model of 'industry-education collaboration' that had special advantages in recruitment:

For most Chinese, going abroad is still a big deal. The students are worried, the parents are also worried. We start the collaboration to make working overseas as a mainstream career choice of the graduates. Now, at matriculation, the college president will mention how many [past students] had gone overseas, to what countries. This will instil in the students' mind a correct conception of going overseas. 
The majority of base intermediaries are however private entities, and for them close ties with the government are crucial. Gold Trust, one of the largest private base intermediaries in Fu Prefecture run by a father and a son surnamed Yang, described itself as an 'attached unit' (guakao danwei; guakao literally meaning 'hang and lean on' ${ }^{3}$ ) to the prefecture labour bureau. Although the affiliation was never officially recognized, the actual relation was strong as seen in the way they worked together on a special government loan scheme. From 2006, the labour bureau provided would-be migrants with interest-free loans up to USD 3,750 per person, which was part of its employment generation campaign. Although all local residents were eligible, only those who applied through Gold Trust were seriously considered. Furthermore, the USD 3,750 was paid to Gold Trust's account to cover the intermediary fees instead of to the migrant directly. In turn Gold Trust guaranteed the payback of the loans once the migrant returned home. Through the connection, Gold Trust was using the government scheme to subsidize its business.

Private base intermediaries are also connected to local government through their 'legs'. Ideal legs are retired government cadres, especially village heads. They have authority in the eyes of the migrants and at the same time know how to deal with documents-the regulated movement of documents being an essential part of legitimate human mobility. Base intermediaries pay a leg USD 150 - 300 for each recruit. The legs in a way turn commercial dealings into interactions between would-be migrants and local government authorities.

The nexus between public and private institutions was further tightened after 2010 when the Ministry of Commerce and CHICA launched the campaign for 'upgrading labour bases to Service Platforms', one of the most important initiatives in regulating labour outmigration in recent years. Directly managed by the local government, a Service Platform comprises a number of public institutions, ranging from training schools to medical clinics to legal offices. A Platform is supposed to monopolize all activities related to recruitment in the locality, from health screening, ticket booking to assistance with return. All window companies have to source migrants from the platforms, and platforms provide workers to licensed windows only (CHICA 2012b, 75-76). The Platforms thus constitute 'enclosed' (fengbishi) channels of recruitment. The Ministry of Commerce in collaboration with other central government agencies set detailed rules about how the Platforms should operate (Ministry of Commerce et al 2010; Ministry of Finance and Ministry of Commerce, 2012), and allocate a considerable amount of funds, USD 5 million in January 2012 alone, to support local government to set up Platforms (CHICA 2012a, 63). By the end of 2014, 257 International Labour Service Platforms were established nationwide (Wen 2015, 44), 
representing a substantial increase from 168 at the end of 2012 (Wen 2013, 9). Large licensed base intermediaries would be incorporated into the Platforms, and smaller players are supposed to be pushed out of business.

\section{'Flexible words'}

The public-private nexus is central to an effective base because, a private intermediary without government backing has little credibility and a public institution without private incentives would not recruit migrants effectively. In spite of the common notion that many Chinese workers desperately wish to migrate, it takes great effort to mobilize a person to pay to migrate. Government staff are not up for the task. Nian Ji, the manager of the window company Five Continent, complained that they are 'too rigid'. 'The way they talk [about migration opportunities] just doesn't sound good.' The CEO of Talent Nets blamed bureaucrats' half-heartedness: 'They don't put their heart in [the business]. If you don't put your heart in (yongxin), you of course can't move others' hearts (dongxin)'.

Effective base intermediaries instead should be good in speaking huohua. Literally meaning living or flexible words, huohua refers to biased but not false descriptions, vague promises that could be reinterpreted. Examples of huohua include telling would-be migrants that they could earn much more than what the contract indicated by working overtime, or they might be able to stay on in the destination, or they may join international companies in China on return given their overseas experiences. 'Contract is dead [fixed], human being are alive [flexible]' (hetong shi si de, ren shi huo de), the intermediaries often told the would-be migrants, 'if the employer likes you, he could do anything for you'. The most important thing therefore, they stressed, is to go overseas first: 'Unless you go out first, you never knew what kinds of life-changing opportunities await you.' 'The riskier, the more profitable', 'where can you find good things that are really guaranteed?' were often heard flexible words.

In order to be persuasive, flexible words must be communicated in face-to-face, informal settings, and they should be mixed with realistic assessments. It is through sustained and intensive communication that would-be migrants make their decisions. In this process, base intermediaries offer not only long hours, but also long lists of choices of jobs and destinations. They also consider the would-be migrant's financial capacity, forthcoming family events, especially weddings and house construction, and even food preference (Korean food would be too spicy for some) when making recommendations. Few would-be migrants start with clear decisions and a base intermediary as a reliable, comprehensive advisor is what they need. Little Yang, the son who manages Gold Trust, told me: 'We used 
to advertise projects [job opportunities], but the effects were so-so. We now advertise ourselves as a company. Then many people come to read the posts [on various projects] on the wall and talk to me.' Whenever I visited the company, the three office rooms were always full, and Little Yang could be seen holding his one-litre size instant Nests Coffee container full of soaked sterculia lychnophora (a type of dried fruit believed to sooth throat) while talking incessantly to multiple visitors. Base staff's familiarity with would-be migrants as a result of long-time communication was important for successful recruitment. As Little Yang puts it: 'Those who are willing to pay so much money [to go abroad] must be special in some regards. They either have some special personality, or have special needs.' If one understands a particular client's special concerns, persuasion is easy.

\section{Control through social relations: Snakes in their old haunts have their way}

'Fujian is immature', said Du Desheng, who migrated to Singapore from Shanghai in the 1980s and later set up his recruitment company specializing in recruiting workers from China. Du explained why Fujian, one of the most important emigration provinces in China since the mid- $19^{\text {th }}$ century, still had a lot of growing up to do:

There are lots of people who are old in age, but they never matured. Fujianese migration is blind migration. They don't develop ‘specialization chains' (zhuanye lian). They are ready to go overseas wherever it is, by whatever means [...] They pay a lot [for it], and then want to do whatever they want.

In other words, Fujian is still green because it does not have systemic rules. In a good base, intermediaries must supplement flexible words with hard discipline. $\mathrm{Wu} \mathrm{En}$, a manager of the Singaporean branch of one of the largest 'window' company in China, agreed, and he thought that base was especially important because Chairman Mao was gone:

Little Xiang, you are young. I still think Mao Zedong was remarkable. He could bring together Chinese people, whose suzhi (human quality) was so low, to build the nation, which the world now has to listen to. Not easy! The Chinese are extremely selfish, have no concept of thinking of the big picture, of collaborating with the company. There is no point to reason with them about collective concerns or the interest of the nation. [...] Bases have their way. They are snakes in their old haunts. 
'Snakes in their old haunts' are often contrasted with powerful dragons in Chinese proverbs, as illustrated by the saying 'powerful dragons lose out to snakes in their old haunts'. Window companies are dragons in the sky but they may be reduced to feeble worms in localities. In one case, when a window requested a county government to punish a migrant who absconded in Japan, the public security bureau shot back accusing the window of human trafficking and demanding the immediate return of the migrant. In another case, a window company sent a team to a village to threaten to evict a migrant's family as the migrant had agreed in the contract to have the house confiscated if he absconded. The team was surrounded by villagers armed with ploughs and spades even before they entered the village. Even if they had managed to get to the house, there was little that they could do. Matters relating to property on allocated residential land (zhaijidi) in the countryside have to have the prior approval of the local land administration. Why should the local government listen to the window staff from far away?

Base intermediaries experimented with different methods of control. Until the late 1990s, base intermediaries collected monetary surety from migrants as the primary or even only means of control. But the amount of monetary bond could not be increased forever; furthermore such bondage was against Chinese government rules, and was frowned upon by overseas employers who believed that the financial burden discouraged good applicants, a concern that was especially strongly expressed by Singaporean employers. Worse, some migrants sought higher-paid jobs illegally in the destination country in order to repay their debts quickly. Under this pressure, bases reduced bond amounts, and instead required wouldbe migrants to name one or more civil servants as guarantors. The guarantors would be held financially accountable to the base for the migrant's wrongdoings overseas. Civil servants are usually the most influential figures in the extended family, and pressure from them is powerful. In enforcing such rules, support from local government of the base place is essential. Huang Shen, a former county cadre and now the director of base intermediary in Fu Prefecture, told me that a turning point in the outmigration from his county was that he, then a cadre, led police to raid a local cadre's home and confiscated the most valuable item, a video player, in 1995 because the cadre refused to pay the fine after the migrant under his guarantorship ran away in South Korea. That created 'shock effects', as he put it, throughout the county as people did not expect the government to take such tough actions. Few dared to violate rules since. In Xin County, a national model base located in Henan province in central China $^{4}$, five civil servants were fired between the mid-1990s and early 2015 because their guaranteed migrants absconded (Li 2015, 19)! ${ }^{5}$ 
Having family members involved is another new method of control. One window company in Liaoning asked its base intermediaries to group families into teams according to the migrants' destinations. In each team a lead family was appointed. They met two or three times a year. Two meetings were particularly important: the one held during the first three months after the workers' departure, and the one around two months before the workers' return. It was felt that during these two periods, workers tended to be 'unstable' and might have 'irrational thinking', as the manager put it.

Recognizing the complexity of mobility management, base intermediaries also turn to psychological tactics. A number of base intermediaries require a third party, normally the would-be migrants' parents, to witness contract signing. The migrant and the witness are photographed together, and the photo is attached to the contract. This is meant to create an impression that a migrant who broke the contract also compromised his/her filial piety. One base intermediary organizes a xuanshi ritual in which the migrant takes a vow never to break laws and contracts. Xuanshi in China is almost exclusively associated with joining the Communist Party or its youth league, where one faces the hammer and sickle flag, right fist raised, and loudly recites the vow of readiness to sacrifice everything for the liberation of the world proletariat. The ritual is again meant to create psychological pressure.

The most important means of ensuring control, pointed out by both bases and windows, is to select the right candidates. Nian Ji, a window company manager, was adamant that he would never recruit workers 'from the society' by which he meant without going through the base, 'I don’t know whether you have a criminal background. I don’t have the time to check. The public security bureau checks on big offences. But what about the small ones?' Nian drew an analogy from the Japanese colonial companies of the 1930s to highlight the importance of base intermediaries in the $21^{\text {st }}$ century:

When the Japanese developed coal mines in the northeast [during the Japanese occupation of Manchuria], they dispatched their own people to the forest to supervise how trees should be cut. All the logs must be of the same size, and must be straight. Then, when they built the mining shaft, it was efficient and safe. Few people died because of the collapse of the structure. Therefore, good management, regardless of in what sector, should always start from the very beginning. [Otherwise] it is very hard to turn a bad worker to be good afterwards. If you are short-tempered, you will always make troubles. [...] So many people want to go overseas, why don't I choose the ones who have been tested and proven (jingguo kaoyan) ${ }^{6}$ 
Window companies rely on bases even when they organize the recruitment themselves. Golden Stage, a window company in Hebei province in north China, recruited workers directly most of the time. A notice issued by the company titled 'Must Knows in Recruitment' urged company staff to ensure that the would-be migrant:

1. must not be from a family with overseas connections;

2. must not be sent to a country where the applicant had been before;

3. must be loyal and reliable;

4. must not be withdrawn, must not experience domestic problems.

In addition to these, Jin Wan, the always smiling director, told me that 'we also look for people who have a strong family attachment, who will miss home. Those who don't miss home are not good persons anyway.’ In order to find workers like this, Golden Stage paid special attention to collaboration from bases. 'I started by going around to visit county governments, talking to the main leaders to gain their understanding and support'. By 2008, Golden Stage signed memos with five counties in Hebei province, which in turn recommended ten villages as bases. The company paid the village heads nearly USD 100 for detailed information on each candidate they recruited. In one instance, a woman who had been chosen for a job in Japan was immediately taken off from the list after the village head reported that she was in the throes of a divorce. 'The woman may be mentally and psychologically unstable when divorcing, and may create problems overseas!' explained Jin Wan, still smiling. Once a villager was recruited, Golden Stage signed a contract with the household head, subjecting the household to fines if the recruit violates rules overseas, and at the same time, it also signed a contract with the village head that obliged the village to enforce the first contract.

\section{'From the people, to the people'}

The involvement of multiple intermediaries in infrastructural governance ensures control, but also increases the uncertainties faced by migrants. For instance chains of intermediaries often lead to 'over recruitment': when a window company expects a number of job offers, their subagents including bases in different places rush into recruitment as the more they recruit, the more money they can make; in the end, a considerably larger number of people than the 
actual offers are promised jobs or even charged service fees. Ironically, such uncertainties compel would-be migrants to stick to bases and legs instead of contacting unknown windows directly. This is because the would-be migrants can keep an eye on the bases and legs all the time. Base intermediaries in turn developed strategies to counter these uncertainties. Some bases monitor the rate of non-selection by windows. If more candidates are rejected than expected in a particular round, they will ask the window to take on more next time in order to protect the bases' reputation in the locality. In addition, the base intermediary Gold Trust holds special sessions with workers both before and after interviews at windows. Old Yang, the father who is the company chairman, told me: 'I give them 'vaccination' beforehand [to be prepared for rejection]. We need to help the workers to establish confidence, then they can stay on [to wait for next migration opportunity]. Many gave up after failed twice; some are angry and spread bad words about us.'

In the case that a would-be migrant lost money for preparing for a migration project that failed to materialize, base intermediaries normally try to help. If the base is a government agency, it may cover the loss by using its discretionary funds, a practice called xiaohua literally to 'digest' - to swallow up the problem. Private bases also tend to shoulder part of the loss. Sometimes they hire stranded would-be migrants as staff as a means of compensation. It seems that the stranded have no problems in persuading others to invest to become would-be migrants. The most substantive and innovative measure to moderate uncertainties that I came across was an insurance scheme put in place by Gold Trust. Gold Trust asked all applicants to complete language (Japanese and Korean) training and medical examinations before being interviewed by the window and the employers, therefore the workers could fly out immediately once selected, which would satisfy the employer's labour need with minimum delays. If an applicant passed the language tests and medical examinations but was not selected, Gold Trust compensated 70 per cent of the cost. (But if the applicant failed the medical examination-the most common cause being Hepatitis B virus positive- - Gold Trust would not compensate regardless of the result of the language tests.) 'Where is the money from?' Old Yang asked rhetorically while explaining the scheme at a regular recruitment seminar open to the public, 'The money is from those who have succeeded in going out. You should all be grateful to them.' 'Quzhi yu min, yongzhi yu min' (from the people, to the people), he stressed. From the people, to the people was a 1980s government slogan to popularize the notion of tax that was alien to most Chinese citizens at that time. The line should not be confused with Mao's 'from the masses, to the masses'. For Mao, the masses are the ultimate political subject and the history maker, and the constant 
back and forth communication between the masses and the vanguard crystalize the will of the masses into revolutionary agendas that in turn facilitated mass actions. For the tax bureau and base intermediary, the people are claimants whose entitlements are determined by their previous contributions. The masses instigate changes, the people as insurance contributors stabilize and absorb uncertainties.

\section{Conclusion}

Migration as a 'bundle of mobilities' (Lin et al, this issue) is not only what researchers discern through an infrastructural perspective (Star 1999), it is how government actually regulates migration. Infrastructural governance manages migration as a wide range of activities embedded in the migrants’ relations with intermediaries, family members, government officials, village cadres and others. An 'infrastructural approach' (Lin et al, this issue) thus aims to capture the emerging reality that the sociotechnical condition in which migration materializes has become a strategic subject of governance.

Infrastructural governance acquires a life of its own. The working of the base shows that government's pursuit of infrastructural power resulted in new power of infrastructure. Commercial intermediaries and local government, who are the central parts of the base, gain advantageous positions. Based on this position, base intermediaries charge high fees, which makes migration more expensive. . This brought about a paradox of infrastructural governance, that is, the liberalization of migration control is accompanied by the complication of migration processes. While the state authorities can no longer deny a citizen's right to exit, local government and commercial intermediaries constantly intervene in how a person think of, prepare for, and act to migrate.

As such the question of how migration is constituted should be considered together alongside how migration is in turn constitutive of larger societal reorganization. In the base for instance, infrastructural governance means that state interventions, market mechanisms and social networks all became deeply entangled in the process of migration production and regulation. The meaning of a locality also changed. A base place is where transnational networks and flows are generated, but is also where transnational momentums are turned into matters of local management. Opposite to the dynamics of 'scale jumping', through which the local becomes the national or even the transnational, as has been observed in globalization and migration (e.g. Harvey 1989; Smith 1993; Swyngedouw 1997), a base 'scales down' the transnational into the local. Finally, the relation between local state and 
society is also affected. The local state became at once more deeply embedded in the local society and more powerful over it. In sum, infrastructural governance provides a useful entry point 'to understand how whole regimes of "legitimate" international travel are being formulated through assemblages of infrastructures that relationally produce different migrancies' (Lin et al., this issue, emphasis original).

By calling attention to the constitutive effects of infrastructural governance, I hope this case study helps to broaden our understanding of the politics of mobility and infrastructure. Recent literature has focused on three questions in the discussion on the politics of mobility: who can move and who can’t (e.g. Bauman 1998; Carling 2002), how different groups move differently (e.g. Salter 2008; Cresswell 2010), and how inequalities are reproduced through mobilities (e.g. Cook and Butz 2016). While the questions of access, differentiation and the reproduction of inequality remain central to any analysis of politics, it is also a fact that in China and many parts of Asia, access to mobility has become much more open and social differentiation less rigid. This article shows that the uneven distribution of power drills deep inside the process of how mobility is infrastructured and at the same time goes far beyond mobility. Careful anatomy of mobility needs to be combined with broad analysis of macro political economy. In this sense, infrastructure can serve as a methodological interface that analytically links together migration as an emergent phenomenon, mobility as what is actually experienced, and larger social reconfigurations that affect migrants and non-migrants alike. 
References

Ali, S. 2007. ““Go West Young Man’: The Culture of Migration among Muslims in Hyderabad, India.” Journal of Ethnic and Migration Studies 33 (1): 37-58.

Bauman, Z. 1998. Globalisation: The Human Consequences. New York: Columbia University Press.

Carling, J. 2002. "Migration in the Age of Involuntary Immobility: Theoretical Reflections and Cape Verdean Experiences.” Journal of Ethnic and Migration Studies 28 (1): 5-42

CHICA (China’s International Contractors’ Association). 2012a. “Duiwai laowu hezuo pingtai jianshe gongzuo zongjie [A Summary of the Work of Developing Service Platforms for International Labour Cooperation].” In 2011-2012 Zhongguo duiwai laowu hezuo fazhan baogao [2011-2012 Annual Report on China International Labour Cooperation], 63-65. Beijing: CHICA.

CHICA (China’s International Contractors’ Association). 2012b. “Duiwai laowu hezuo pingtai jianshe zhidao yijian [Guiding Suggestions on the Development of Service Platforms for International Labour Cooperation].” In 2011-2012 Zhongguo duiwai laowu hezuo fazhan baogao [2011-2012 Annual Report on China International Labour Cooperation], 75-77. Beijing: CHICA.

CHICA (China’s International Contractors’ Association). 2004. “Duiwai laowu hezuo hangye waipai laowu jidi zhidao banfa (shixing) [Provisional Guidelines on Labour Dispatch Bases in the Business of International Labour Cooperation].” Issued on 20 February. Beijing: CHICA.

CHICA (China’s International Contractors’ Association). 2015. “Gaishu [Summary ].” In 2014-2015 Zhongguo duiwai laowu hezuo fazhan baogao [2014-2015 Annual Report on China International Labour Cooperation], 5-8. Beijing: CHICA.

Chu, J. Y. 2010. Cosmologies of Credit: Transnational Mobility and the Politics of Destination in China. Durham: Duke University Press. 
Collier, S. 2011. Post-Soviet Social: Neoliberalism, Social Modernity, Biopolitics. Princeton: Princeton University Press.

Cook, N., and D. Butz. 2016. “Mobility Justice in the Context of Disaster.” Mobilities 11 (3): 400-419.

Cresswell, T. 2010. “Towards a Politics of Mobility.” Environment and Planning D: Society and Space 28 (1): 17-31.

Dou, X. J. 2004. “Dangqian guoji laowu shichang fazhan taishi jiqi yingdui celue [Development trends of the international labour market and our coping strategies].” Zhiye jishu jiaoyu [Vocational and Technical Education] 23 (31): 14-18.

Findlay, A. M., and F. L. Li. 1997. “An Auto-Biographical Approach to Understanding Migration: The Case of Hong Kong Emigrants.” Area 29 (1): 34-44.

Gao, G. J. 2000. “Economic, Labour Market and Migration Developments in China.” In Labour Migration and the Recent Financial Crisis in Asia, 73-83. Paris: OECD.

Gardner, K. 1995. Global Migrants, Local Lives: Migration and Transformation in Rural Bangladesh. Oxford: Oxford University Press.

Harvey, D. 1989. The Condition of Postmodernity. Oxford: Basil Blackwell.

He, X. K., ed. 1994. Guoji laowu hezuo shiwu [Practice of International Labor Cooperation]. Beijing: Beijing Gongye Daxue Chubanshe [Beijing Industrial University Press].

Horvath, I. 2008. “The Culture of Migration of Rural Romanian Youth.” Journal of Ethnic and Migration Studies 34 (5): 771-786.

Hull, M. 2008. "Ruled by Records: The Appropriation of Land and the Misappropriation of Lists in Islamabad.” American Ethnologist 34 (4): 501-518.

Kandel, W., and D. Massey. 2002. “The Culture of Mexican Migration: A Theoretical and Empirical Analysis.” Social Forces 80 (3): 981-1004.

Larkin, B. 2013. “The Politics and Poetics of Infrastructure.” Annual Review of Anthropology 42: 327-343. 
Levitt, P. 2001. The Transnational Villagers. Berkeley: University of California Press.

Li, X. X. 2015. “Chengwei ‘yang gongren’: Henan xinxian duiwai laowu shuchu jizhi yanjiu [Becoming 'Overseas Workers’: A Research on the Mechanism of International Labor Outmigration in Xin County, Henan].” BA diss., College of Humanities and Development, China’s Agriculture University.

Lin W. Q., J. Lindquist, B. Xiang, and B. Yeoh. 2017. "Migration Infrastructures and the Production of Migrant Mobilities”. Mobilities, this issue.

Lindquist, J., and B. Xiang. Forthcoming. “The Infrastructural Turn in Asian Migration.” In Routledge Handbook of Asian Migrations, edited by G. Liu-Farrer and B. Yeoh. London: Routledge.

Liu, G. F. 2007. The Right to Leave and Return and Chinese Migration Law. Leiden: Martinus Nijhoff Publishers.

Liu, G. F. 2009. “Changing Chinese Migration Law: From Restriction to Relaxation.” Journal of International Migration and Integration 10 (3): 311-333.

Long, G. Q. 1995. Zhongguo fuwu maoyi [Trade in Service from China]. Beijing: Zhongxin chubanshe [CITIC Press].

Mann, M. 1984. "The Autonomous Power of the State: Its Origins, Mechanisms and Results.” European Journal of Sociology 25 (2): 185-213.

Massey, D., J. Arango, G. Hugo, A. Kouaouci, A. Pellegrino, and J. Taylor. 1993. “Theories of International Migration: A Review and Appraisal.” Population and Development Review 19 (3): 431-466.

Mazzarella, W. 2004. “Culture, Globalization, Mediation.” Annual Review of Anthropology 33: $345-367$.

Ministry of Commerce, Ministry of Foreign Affairs, Ministry of Public Security, and the State Administration of Industry and Commerce. 2010. "Duiwai laowu hezuo fuwu pingtai jianshe shixing banfa [Provisional Procedures for the Development of International Labor Cooperation Service Platforms].” Issued July 1, Shang He Han No. 484. 
Ministry of Commerce. 2016. “2015 nian woguo duiwai laowu hezuo yewu jianmin tongji [Concise statistics of China”s foreign labor cooperation in 2015].” Accessed 17 September 2016. http://hzs.mofcom.gov.cn/article/date/201601/20160101239878.shtml

Ministry of Finance, and Ministry of Commerce. 2012. “Guanyu zuohao 2012 nian duiwai laowu hezuo fuwu pingtai zhichi zijin guanli gongzuo de tongzhi [Notice on Proper Management of Supporting Fund for International Labor Cooperation Service Platforms].” Issued August 17, Code Caiqi No. 217.

Ministry of Labour and Social Security, Ministry of Public Security, and State Administration of Industry and Commerce. 2002. “Jingwai jiuye zhongjie guanli guiding [Provisions on the Administration of Intermediary Activities for Overseas Employment].” Decree 15 issued on 14 May. Accessed 17 September 2016. http://baike.baidu.com/view/404665.htm

Pieke, F., P. Nyíri, M. Thunø, and A. Ceddagno. 2004. Transnational Chinese: Fujianese Migrants in Europe. Stanford: Stanford University Press.

Reichert, J. 1981. “The Migrant Syndrome: Seasonal U.S. Wage Labor and Rural Development in Central Mexico.” Human Organization 40: 56-66.

Salter, M. B., ed. 2008. Politics at the Airport. Minneapolis: University of Minnesota Press. Smith, N. 1993. “Homeless/Global: 'Scaling Places.” In Mapping the Futures: Local Culture, Global Change, edited by J. Bird, B. Curtis, T. Putnam, G. Robertson, and L. Tucker, 87-119. London: Routledge.

Star, S. L. 1999. “The Ethnography of Infrastructure.” American Behavioral Scientist 43 (3): 377-391.

Sun, Z. M., and H. P. Zhou. 2014. “Jiannan nie pan, huali zhuanshen: Henan xinxian duiwai laowu hezuo fazhan moshi zhuanxing jishi [Painful Nirvana, Glorious rebirth: Documenting the Transformation of the Development Model of International Labor Cooperation in Xin County, Henan].” Guoji gongchen yu laowu [International Project Contracting and Labour Service] 1: 47-49. 
Swyngedouw, E. 1997. "Neither Global Nor Local: “Globalisation” and the Politics of Scale.” In Spaces of Globalization: Reasserting the Power of the Local, edited by K. Cox, 137166. New York: Guilford Press.

Wen, Y. 2013, “2012 nian zhongguo duiwai laowu hzuo fazhan shuping [Summaries and Comments on China’s International Labor Service for 2012].” Guoji gongchen yu laowu [International Project Contracting and Labour Service] 3: 8-11.

Wen, Y. 2015. "2014 nian zhongguo duiwai laowu hzuo fazhan shuping [Summaries and Comments on China”s International Labor Service for 2014].” Guoji gongchen yu laowu [International Project Contracting and Labour Service] 3: 42-46.

Xiang, B. 2003. “Emigration from China: A Sending Country’s Perspective.” International Migration 41 (3): 21-48.

Xiang, B., and J. Lindquist. 2014. “Migration Infrastructure.” International Migration Review 48: S122-S148.

Yang, D. L. 2004. Remaking the Chinese Leviathan: Market Transition and the Politics of Governance in China. Standford: Stanford University Press.

Yin, H. 2002. “Gaige kaifang yilai zhongguo duiwai laowu shuchu fazhan zongshu [A Summary of China's International Labour Outmigration since the Reform and OpenUp].” Renkou Xuekan [Population Journal] 6: 12-17.

“Zhongguo duiwai jingji maoyi chubanshe [China International Economy and Trade Publisher].” 1991. In Zhongguo duiwai jingji maoy nianjian 1990 [Yearbook of China”s International Economy and Trade 1990]. Beijing: Zhongguo duiwai jingji maoyi chubanshe [China International Economy and Trade Publisher].

\footnotetext{
${ }^{1}$ The distribution of Chinese migrant workers by occupation changed little since the end of 1990s. About 40 percent of Chinese migrants worked in manufacturing industries (especially textiles and food processing), with 25 percent in construction and 15 percent in agriculture, forestry, and fishing industries. Less than 0.5 percent worked on white-collar jobs. In terms of destination, the Middle East, particularly Iraq and Kuwait, was the largest in the 1980s. From the mid-1990s onwards however East and Southeast Asia are responsible for more than 70 percent of all migrant workers (Yin 2002; CHICA 2015, 6).
} 


\footnotetext{
${ }^{2}$ The Foreign Economic Liaison Ministry, later the Ministry of Foreign Technology and Economic Cooperation and then the Ministry of Commerce, managed project-based labour deployment since the 1950s up to now. In 1992 the Labour Ministry was tasked to manage individually initiated labour outmigration, but the line between project-based and individually-initiated migrations was never clear cut. Between 2002 and 2010 the Labour Ministry actively promoted market-oriented style of management of labour outmigration of all types, especially by giving commercial intermediaries a central role. The Ministry of Commerce initiated similar reforms.

Infrastructural governance became the mainstream. In 2010 the central government designated the Ministry of Commerce as the primary agency in charge of outmigration, regardless of being project-tied or not.

${ }^{3}$ It was a common practice in the 1980s that small private businesses affiliated themselves with SOEs or public institutions in order to access production materials and bank loans that were tightly controlled. This

phenomenon largely disappeared in economic sectors, but guakao was still essential for many NGOs to survive in China.

${ }^{4}$ Xin County is possibly the largest base of labour outmigration in China, which sent a total of 23,000 workers overseas between 1994 and 2014. The County Bureau for International Labour Cooperation, a government base intermediary, accumulated an asset of over USD 16 million by 2014 through the recruitment business. Sun and Zhou $(2014,47)$.

${ }^{5}$ The guarantee system in Xin County is particularly elaborate. Each would-be migrant has to identify one civil servant and two immediate relatives as guarantors. If the migrant absconded, the civil servant would be fired and all the guarantors would pay a fine of more than USD 8,500 each. In order to be a guarantor, the civil servant must have local household registration record and have a permanent job in a public institute that is not a bank or other types of finance institute, must be younger than 55 (for man) or 50 (woman), and must not be eligible for early retirement (Li 2015, 18-19).

${ }^{6}$ Jingguo kaoyan is a Chinese Communist Party terminology, meaning a member has proven his/herself in difficult condition and is therefore ready for promotion.
} 